\title{
A case of endoscopic hemostasis using double-balloon endoscopy for an intestinal hemorrhage in a giant incisional hernia
}

A 62-year-old man was referred to Chiba University Hospital with melena. He had previously suffered from severe peritonitis due to appendicitis and consequently had a giant abdominal incisional hernia. Although his appearance was pale due to a hemoglobin concentration of $6.9 \mathrm{~g} / \mathrm{dL}$, his vital signs were stable. His abdomen was distended in the right side because of, not only the hernia, but also his severe obesity; he had a body mass index of $42.3 \mathrm{~kg} / \mathrm{m}^{2}$ (> Fig. 1).

An abdominal computed tomography scan clearly demonstrated the giant incisional hernia, which included the jejunum, ileum, and ascending colon ( Fig.2). No suspected bleeding point was found during esophagogastroduodenoscopy and small-bowel capsule endoscopy; however, transoral and transanal double-balloon endoscopy (DBE) were performed when the patient presented with melena ( Fig. 3 ). We found a small Dieulafoy's lesion with pulsatile bleeding in the lower section of the ileum, and performed hemostatic clipping for the lesion ( Video 1). Rebleeding was not seen after clipping, and the patient was discharged.

There are no reports on endoscopic hemostasis using DBE for an intestinal hemorrhage in a giant incisional hernia. The presence of an abdominal hernia is not a contraindication to colonoscopy [1]. Careful assessment by physical examination and radiological images before endoscopy is important because this can alert an endoscopist to potential risks, such as perforation and incarceration, especially in the case of an incisional hernia [2,3]. Furthermore, although DBE has not been found to be superior to other deep enteroscopy techniques, such as single-balloon endoscopy and spiral endoscopy, for increasing diagnostic or therapeutic yields, the rate of com-

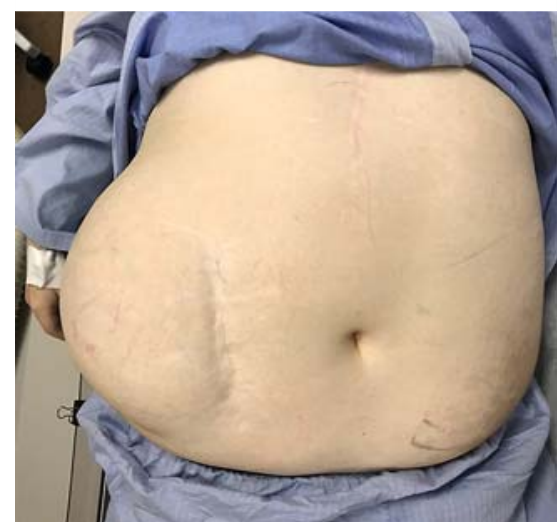

- Fig. 1 Physical examination showed severe obesity, and distension in the right side of the abdomen.

plete enteroscopy with DBE has been shown to be higher than the rate with other techniques $[4,5]$.

To conclude, endoscopic hemostasis by DBE should be considered in cases with a giant incisional hernia.
Endoscopy_UCTN_Code_CCL_1AC_2AB

Competing interests

None

The Authors

Takashi Taida, Tomoo Nakagawa, Yuki Ohta, Shinsaku Hamanaka, Kenichiro Okimoto, Daisuke Maruoka, Tomoaki Matsumura, Makoto Arai

Department of Gastroenterology and Nephrology, Graduate School of Medicine, Chiba University, Chiba, Japan

\section{Corresponding author}

\section{Tomoo Nakagawa, MD}

Department of Gastroenterology, Graduate School of Medicine, Chiba University, Inohana 1-8-1, Chiba, 260-8670, Japan Fax: +81-43-2262088

tom20852@hospital.chiba-u.jp

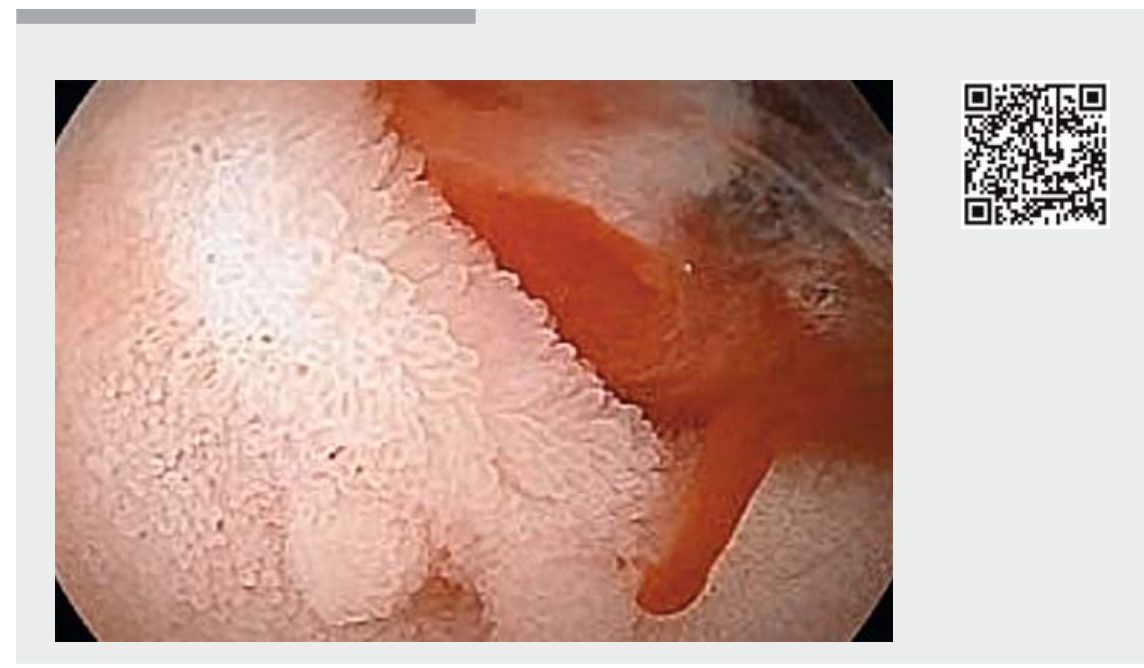

Video 1 Double-balloon endoscopy was performed to evaluate intestinal bleeding. Hemostatic clipping was performed for a bleeding intestinal Dieulafoy's ulcer. 

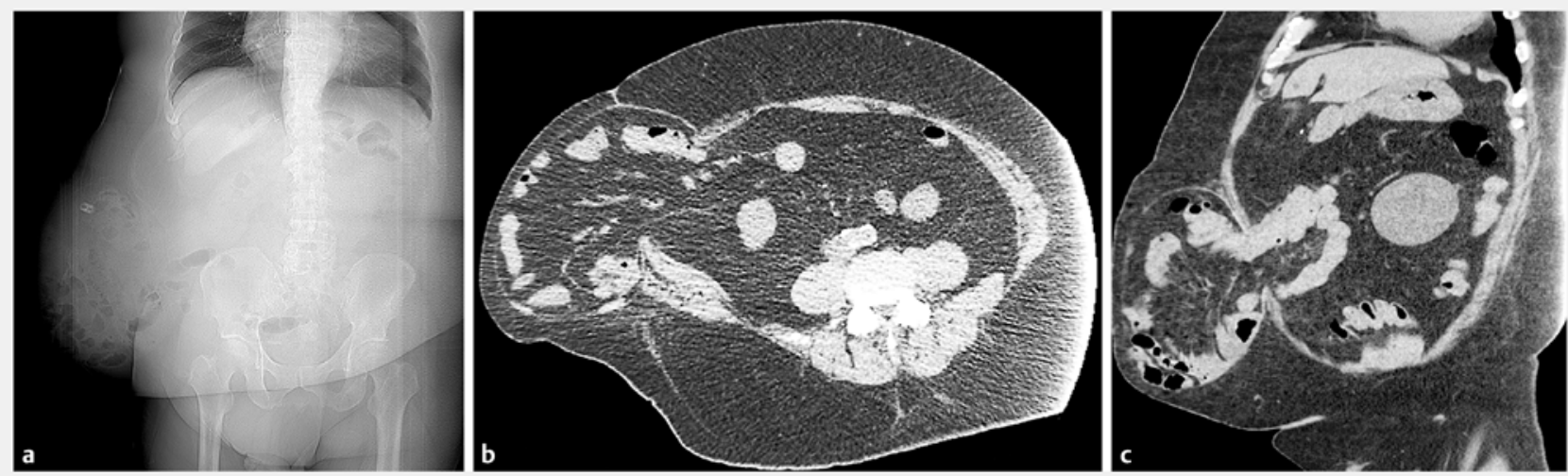

Fig. 2 Abdominal computed tomography scan. a Giant incisional hernia, including the jejunum, ileum, and ascending colon, was visible on the X-ray image. $\mathbf{b}$ The axial view. $\mathbf{c}$ The coronal view.
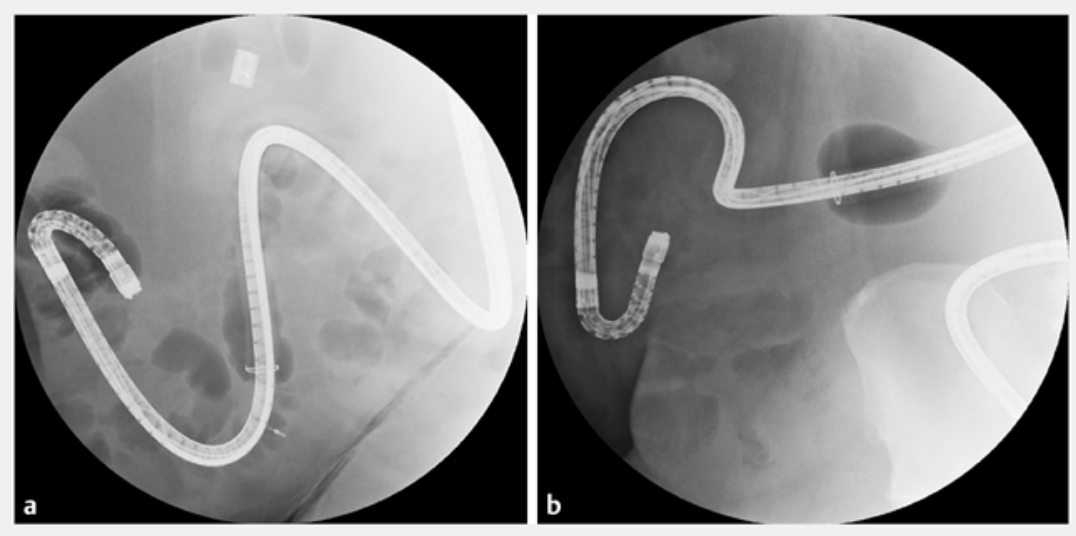

Fig. 3 Fluoroscopic view of double-balloon endoscopy. a Transoral insertion to the jejunum, including the giant incisional hernia. $\mathbf{b}$ Transanal insertion to the ileum and ascending colon, including the giant incisional hernia.

\section{References}

[1] Yamamoto K, Kadakia CS. Incarceration of a colonoscope in an inguinal hernia. Gastrointest Endosc 1994; 40: $396-397$

[2] Ladumer R, Mussack T. Small bowel perforation due to protruding spiral trackers: a rare complication in laparoscopic incisional hernia repair. Surg Endosc 2004; 18: 1001

[3] Tanishima H, Shono Y, Sakaguchi S et al. Incarceration of a colonoscope in an inguinal

\section{Bibliography}

DOI https://doi.org/10.1055/s-0043-111712

Published online: 18.7.2017

Endoscopy 2017; 49: E221-E222

(c) Georg Thieme Verlag KG

Stuttgart · New York

ISSN 0013-726X

\section{ENDOSCOPY E-VIDEOS}

https://eref.thieme.de/e-videos

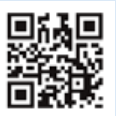

Endoscopy E-Videos is a free access online section, reporting on interesting cases and new

techniques in gastroenterological endoscopy. All papers include a high quality video and all contributions are freely accessible online.

This section has its own submission website at

https://mc.manuscriptcentral.com/e-videos ized, controlled trial. Gastrointest Endosc 2011; 73: 734-739

[5] Jeon SR, Kim JO. Deep enteroscopy: which technique will survive? Clin Endosc 2013;

46: 480

hernia and laparoscopic findings. Dig Endosc 2012: 24: 486

Takano N, Yamada A, Watabe $\mathrm{H}$ et al. Singleballoon versus double-balloon endoscopy 